\title{
Şanlıurfa'da Gebe Kadınların İlaç Kullanım Alışkanlıkları ve Etkileyen Faktörler
}

\section{Drug Use Habits and the Effective Factors of Pregnant Women in Sanliurfa}

\author{
PInar Çağlar ALPTEKIN ${ }^{1}$, Fatma KORUK ${ }^{2}$
}

\author{
1 Harran Üniversitesi Sağık Bilimleri Enstitüsü Hemşirelik Anabilim Dalı, Şanlıurfa \\ 2 Harran Üniversitesi Sağlık Bilimleri Fakültesi Doğum ve Kadın Hastalıkları Hemşireliği Anabilim Dalı, Şanlıurfa
}

Öz.

Amaç: Calıșma, Șanlıurfa'da gebe kadınların ilaç kullanım alıșkanılıklarını ve etkileyen faktörleri belirlemek amacıyla yapılımıștır. Materyal ve Metod: Tanımlayıcı tipte olan araştımanın evrenini, Şanlıurfa'da bir eğitim araştırma hastanesinin kadın doğum polikliniklerine başvuran gebeler oluşturmuştur. Örnek büyüklügü; konuyla ilgili çalışmalar dikkate alınarak tahmini orant//oran/sıklık \%27,8, hata sınırı $\% 5$ ve $\% 95$ güvenle yapılan hesaplamada 309 olarak hesaplanmıștır. Veriler, Tanımlayıcı Veri Toplama Formu aracilığı ile Şubat-Mayıs 2016 tarihleri arasında, yüz yüze görüşme tekniği kullanılarak toplanmıştır. Araştırmada, Harran Üniversitesi Etik Kurulu’ndan ve Kamu Hastaneler Birliği Genel Sekreterliği'nden yazılı izin, çalıșmaya katılmayı kabul eden gebe kadınlardan sözlü onam alınmışır. Verilerin değerlendirilmesinde, tanımlayııı istatistiklerden yüzde, ortalama ve standart sapma; tek değișkenli analizlerden Ki-kare testi kullanııııștır.

Bulgular: Gebelerin \%76,1'i gebeliği boyunca en az bir ilaç kullanmaktadır. Gebelerin \%23,6'sının doktora danışmadan ilaç kullandığı ve bu ilaçlar içerisinde en fazla analjeziklerin $(\% 21,4)$ olduğu belirlenmiştir. Gebelerin $\% 74,4$ ü doktordan ilaç hakkında bilgi istediğini, \%63,8'i ilaçların prospektüsünü okuduğunu, \%98,1'i ilacı doktorun önerdiği sekilde kullandığını, \%57.6'sı ilacın kullanımında saat aralıklarına ve \%74.1'i ilacın dozuna dikkat ettiğini, \%64.4'ü evde bulunsun diye ilaç yazdırmadığını bildirmiştir. Yapılan istatistiksel değerlendirmede; gebelerin doktora danışmadan ilaç kullanım durumları ile sosyo-demografik özellikleri ve kronik hastalığı olma durumları açısından aralarında fark olmadığı belirlenmiştir $(p>0.05)$.

Sonuç: Çalışma sonuçlarına göre, gebelerin çoğunluğunun doğru ilaç kullanım alışkanlığına sahip olduğu belirlenmiştir. Bu sonuçlar doğrultusunda, gebelerde doğru ilaç kullanımının yaygınlaştıııması, gebelik izlemlerinde ilaç kullanım alışkanlıklarının da sorgulanması, gerekli durumlarda ilaç kullanımına yönelik gebe ve ailesine eğitim ve danışmanlık yapııması, hemşirelerin ilaç kullanımı konusunda bilgilerinin güncel tutulması ve konuya duyarıııklarının artıııması önerilmiştir.

Anahtar kelimeler: Gebe, Illaç, Hemşirelik.

Abstract

Background: The aim of the study was to determine the drug use habits and factors affecting pregnant women in Sanliurfa Materials and Methods: The study was conducted in descriptive type. The population of this descriptive study was composed of the pregnant women who applied to the obstetrics and gynecology clinics of an educational research hospital in Sanliurfa. Sample size was calculated as 27.8\%, error limit 5\% and 309\% in the calculation with 95\% confidence. February- May 2016 through the descriptive data collection form, the data was collected using the face-to-face interview technique. In the study, written permission was obtained from Harran University Ethics Committee and General Secretariat of Public Hospitals Association and oral consent was obtained from pregnant women who agreed to participate in the study. In the evaluation of the data, percentage, mean and standard deviation from descriptive statistics and Chi-square test from univariate analyses were used.

Results: $76.1 \%$ of pregnant women use at least one drug during pregnancy. It was determined that $23.6 \%$ of the pregnant women used drugs without consulting the doctor and that they used the most analgesics $(21.4 \%)$ within these drugs. $74.4 \%$ of pregnant women asked the doctor for information about the drug, $63.8 \%$ read the drug prospectus, $98.1 \%$ used the drug as recommended by the doctor, $57.6 \%$ of the drug use hours intervals and $74.1 \%$ of the drug dose attention, $64.4 \%$ of the drug to be found at home reported that they did not print. Statistical evaluation; it was determined that there was no difference between the drug use status and socio-demographic characteristics of the pregnant women and their chronic disease status without consulting the doctor $(p>0.05)$.

Conclusions: According to the results of the study, it was found that the majority of pregnant women had the right drug habit. According to these results, the dissemination of right drug use in pregnant women, pregnancy monitoring drug use in questioning habits, if necessary, for drug use training and consultancy services to pregnant women and families, nurses be kept up to date information about drug use and have been proposed to increase the sensitivity of the topic.

Key words: Pregnant, Drug, Nursing.

\section{Sorumlu Yazar I \\ Corresponding Author}

Doç. Dr. Fatma KORUK Harran Üniversitesi

Sağlık Bilimleri Fakültesi

Osmanbey Kampüsü

Merkezi Derslikler Binası 2. Kat

Haliliye / ŞANLIURFA

Telefon: (0542) 7240212

Fax: (0414) 3183203

e-mail: fgozukara18@gmail.com

Geliş tarihi / Received: 22.10.2019

Kabul tarihi / Accepted: 21.02.2020

\section{DOI: $10.35440 /$ hutfd. 636080}

${ }^{*}$ Bu çalışma Pınar Çağlar ALPTEKIN'in Yüksek lisans

Tezinden üretilmiştir ve 19-21 Aralık 2019 tarihinde Ankara'da yapılan 6. Uluslararası 17. Ulusal Hemşirelik Kongresi'nde sözlü sunum olarak sunulmuştur. 


\section{Giriş}

Gebelikte ilaç kullanımı hem annenin hem de fetüsün sağlığını yakından ilgilendiren önemli bir konudur (1). Kullanılan ilaçlar, gebelikte değişen fizyoloji ve anatomi nedeniyle gebeye uygulanan tedavilerin farmakokinetiğini değiştirmekle beraber, birtakım tedavi edici ajanların tahmin edilenden daha fazla plasenta yoluyla fetüse geçerek teratojenik etki göstermesine neden olabilmektedir $(2,3)$. Konjenital anomalilerin \%4-6'sı kullanılan ilaçlara bağlı teratojenlerden, bebek ölümlerinin \%20.0' si ise ilaç kullanımlarından kaynaklanmaktadır (4).

Yapılan çalışmalarda gebe kadınların \%80.0' ninden fazlasına en az bir kez ilaç reçete edildiği, her geçen gün gebelikte ilaç kullanım oranlarının artıığ belirtilmektedir $(1,5)$. Türkiye'de yapılan çalışmalarda, gebelerde ilaç kullanım sıklığının \%27.8 (6) olduğu, yüksek riskli grupta yer alan ilaç kullanımının \%9.8 (7) ve ilaç kullanımı nedeniyle sonlandırılan gebelik oranının \%33.3 (8) olduğu belirtilmektedir.

Gebelikte kullanılan ilaçlar, gebelik durumunu bilmeden kullanılanlar, gebelikte kullanılması gerekenler (vitamin, mineral), kronik bir hastalığa sahip olup (diyabet, astım, hipo/hipertansiyon, imflamatuvar bağırsak hastalı̆ı̆, epilepsi vb.) buna bağı kullanılması gerekenler ve gebelikte oluşan yeni bir hastalık durumunun tedavisi için kullanılanlar olarak kategorize edilmektedir $(1,5)$. Gebelikte ilaç maruziyetinin en sık karşılaşıldığı dönem gebeliğin bilinmediği dönemdir (9).

İlaç kullanımı, insan sağlığının korunması ve sürdürülmesinde etkili bir yöntemdir. Fakat kontrollü bir şekilde gerçekleştirilmeyen ilaç kullanımı gerek insan sağlığının bozulmasına gerekse ekonomik ve sağlık işgücü gibi birçok değerin kaybına neden olabilmektedir (10). İlaç kullanan gebenin teratojenik risklerin değerlendirilebilmesi için verilerinin kayıt altına alınması, prenatal ve postpartum takiplerinin düzenli yapılması önemlidir (11-12).

Şanlıurfa doğurganlığın (toplam doğurganlık hızı 4.1) fazla olduğu, dolayısıyla gebe nüfusun yüksek olduğu bir ildir (13). Bu açıdan değerlendirildiğinde bu bölgede gebelerin ilaç kullanım alışkanlıklarının takip edilmesi anne bebek sağlığı açısından daha fazla önem kazanmaktadır. Bu nedenle çalışma, Şanlıurfa'da gebe kadınların ilaç kullanım alışkanlıklarını ve etkileyen faktörleri belirlemek amacıyla yapılmıştır.

\section{Materyal ve Metod \\ Araştırmanın Tipi \\ Araştırma tanımlayıcı tipte yapılmıştır. \\ Yürütüldüğü Tarih}

Araştırma, Şubat 2017-Mayıs 2019 tarihleri arasında yürütülmüştür.

\section{Araștırmanın Evreni ve Örneklem Seçimi}

Araştırmanın evrenini, Şanlıurfa'da bir eğitim araştırma hastanesinin kadın doğum polikliniklerine başvuran gebeler oluşturmuştur. Örnek büyüklüğü ise; Türkiye'de gebelerde ilaç kullanım sıklığının incelendiği çalışma (6) dikkate alınarak, tahmini orantı/oran/sıklık \%27.8, hata sınırı $\% 5$ ve $\% 95$ güvenle yapilan hesaplamada 309 olarak hesaplanmıştır. Örneklemin tamamına ulaşılmıştır.

\section{Verilerin Toplanması}

Veriler, veri toplama formu aracılığıyla yüz yüze görüşme tekniği kullanılarak toplanmıştır. Veri toplama formu; sosyo-demografik özelliklerini (yaş, öğrenim düzeyi, ekonomik durum, çalışma durumu, eşinin öğrenim düzeyi, eşinin çalışma durumu, sosyal güvenceleri, evde en çok konuşulan dil, aile tipi, nerde yaşadıkları ve kronik bir hastalığın olup olmama durumunu) içeren 10 soru, doğurganlık özelliklerini (gebelik haftası, toplam gebelik sayısı, yaşayan çocuk sayısı, gebeliğin planlı olup olmadığını, gebelikle ilgili yaşadığı problemleri) içeren 5 soru ve ilaç kullanım alışkanlıklarını içeren 27 soru olmak üzere toplam 42 sorudan oluşmaktadır.

\section{Verilerin Değerlendirilmesi}

Araştırmadan elde edilen veriler, bilgisayar ortamında Statistical Package for Social Sciences (SPSS) for Windows 16.0 istatistik paket programı kullanılarak araştırmacı tarafından değerlendirilmiştir. Verilerin değerlendirilmesinde; tanımlayıcı istatistiklerden yüzde, ortalama, ortanca, standart sapma ve tek değişkenli analizlerden Ki-kare testi kullanılmıştır. Bulgular \%95.0 güven aralığında 0.05 anlamlılık düzeyinde yorumlanmıştır.

\section{Araştırmanın Etik Boyutu}

Araştırmanın yapılabilmesi için Kamu Hastaneler Birliği Genel Sekreterliği'nden ve Harran Üniversitesi Etik Kurulu'ndan (01.09.2016 tarih ve 07 sayılı) yazılı izin, çalışmaya katılmayı kabul eden gebelerden ise bilgilendirilmiş sözlü onam alınmıştır.

\section{Bulgular}

Gebelerin yaş ortalaması $26 \pm 5.8^{\prime}$ dir ve $\% 48.8^{\prime} i$ herhangi bir eğitim kademesini tamamlayamamıştır. Gebelerin $\% 30.1$ 'nin sosyal güvencesi bulunmamakta ve $\% 68.3$ 'ü ekonomik durumunu "orta" olarak değerlendirmektedir. Gebelerin \%88.3'ü çalışmamakta, çalışanların ise \%61.1' i tarım işçiliği yapmaktadır. Gebelerin \% 39.5'i evde en çok Arapça konuşmakta, \%57.0'si il merkezinde ve $\% 52$.1'i çekirdek ailede yaşamaktadır. Gebelerin eşlerinin \%23.6'sı herhangi bir eğitim kademesini tamamlayamamış, \%83.8'si çalışmakta ve çalışanların büyük bölümü işçilik yapmaktadır (\%49.0).

Gebelerin gebelik haftası ortalaması $25.6 \pm 9.8$, toplam gebelik sayısı ortalaması $3.2 \pm 2.17$ ve yaşayan çocuk sayısı ortalaması $1.8 \pm 1.8$ 'dir. Gebelerin \%54.7'sinin gebeliği plansızdır, \%45.3'ünün gebeliğe bağlı en az bir rahatsızığı vardır.

Gebelerin \%76.1'i gebelik sürecinde ilaç kullanmaktadır ve 
bu ilaçlar çoğunlukla vitamin (\%60.5) ve demir preparatlarıdır (\%49.5). Gebelerin \%22.3'ü en az bir aydır ilaç kullanmaktadır. Illaç kullanan gebelerin tamamı bu ilaçların doktor tarafından önerildiğini (\%100.0) ve çoğunluğu (\%71.2) kullandığı ilacın bebeğine zarar vermediğini düşündüğünü belirtmiştir.

Gebelerin \%76.4'ü doktora danışmadan ilaç kullanmamaktadır. Doktora danışmadan ilaç kullanan gebeler (\%23.6) ise, en çok \%21.4 ağrı kesici, \%8.1 antibiyotik grubu ilaçlar kullanılmaktadır. Gebelerin \%75.1'inin doktora danışmadan antibiyotik kullanma alışkanlığı yoktur (Tablo 1).

Tablo 1. Gebelerin Doktora Danışmadan Illaç Kullanımına Illişkin Özelliklerinin Dağılımı

\begin{tabular}{|c|c|c|}
\hline Tanıtıcı Özellikler & Sayı & $\%$ \\
\hline \multicolumn{3}{|c|}{ Doktora Danışmadan İlaç Kullanma Durumu } \\
\hline Kullanıyor & 73 & 23.6 \\
\hline Kullanmıyor & 236 & 76.4 \\
\hline \multicolumn{3}{|l|}{ Kullanılan İlaçlar* } \\
\hline Ağrı kesiciler & 66 & 21.4 \\
\hline Ateş düşürücüler & 16 & 5.2 \\
\hline Antibiyotik & 25 & 8.1 \\
\hline Antigribal & 12 & 3.9 \\
\hline Peptik ülser ilaçları & 10 & 3.2 \\
\hline Gis ilaçları & 2 & 0.6 \\
\hline Antihipertansif & 1 & 0.3 \\
\hline Antihistaminik & 1 & 0.3 \\
\hline Vitamin & 4 & 1.3 \\
\hline Doğum kontrol ilaçları & 1 & 0.3 \\
\hline \multicolumn{3}{|c|}{ Doktora Danışmadan Antibiyotik Kullanma Durumu } \\
\hline Kullanırım & 77 & 24.9 \\
\hline Kullanmam & 232 & 75.1 \\
\hline
\end{tabular}

Gebelerin \%12.0'si akraba, arkadaş, komşu tavsiyesi ile ilaç kullanmakta ve bu ilaçlar çoğunlukla (\%70.3) ağrı kesiciler olmaktadır. Gebelerin \%14.2'si akraba, arkadaş ve komşularına ilaç tavsiye etmemişlerdir. Tavsiye eden (\%14.2) gebeler ise en çok \%86.4 ağrı kesici ve \%9.1 antibiyotik ilaçları tavsiye etmişlerdir. Gebelerin \%83.8'inin antibiyotikleri bitirmeden bırakma alışkanlığı vardır. Antibiyotik ilaçları bitirmeden bırakan gebelerin \%45.6'sı iyileşme nedeniyle, \%21.6'sı kendini iyi hissetme nedeniyle, \%18.5'i fazla ilaç almamak için, \%7.7'si unutkanlıktan, \%2.3'ü bebeğine zarar vereceğini düşündüğü için antibiyotikleri bitirmeden bıraktığını bildirmiştir.

Gebelerin ilaç kullanımına yönelik bilgi ve tutumları sorgulandığında; \% 74.4'ünün reçete edilen ilaç hakkında doktordan bilgi istediği, \%64.1'inin ilacın prospektüsünü okuduğu (prospektüste en çok okudukları yerler \%51.1 ilaç endikasyonları ve $\% 42.1$ yan etkilerdir), $\% 98.1$ 'inin ilacı doktorun önerilerine uygun şekilde kullandığı, \%84.5'inin açlık-tokluk durumuna, $\% 57.6$ 'sının saat aralıklarına ve $\% 74.1$ 'inin ilaç dozunu dikkate aldığı, \%52.4'ünün ilacı kullanırken istenmeyen yan etki görüldüğünde doktora başvurduğu, \%37.9'unun ilaçtan yarar görmediğinde ilacı bıraktığı, \%75.4' ünün ilaçları kullanmadan önce ilacın son kullanma tarihine baktığı, \%35.6'sının evde bulunsun diye ilaç yazdırma alışkanlığının olduğu (\%81.8'i ağrı kesici ilaçlar yazdırmıştır) belirlenmişstir (Tablo 2).

Tablo 2. Gebelerin Illaç Kullanımında Bilgi ve Tutumlarının DağıIImI

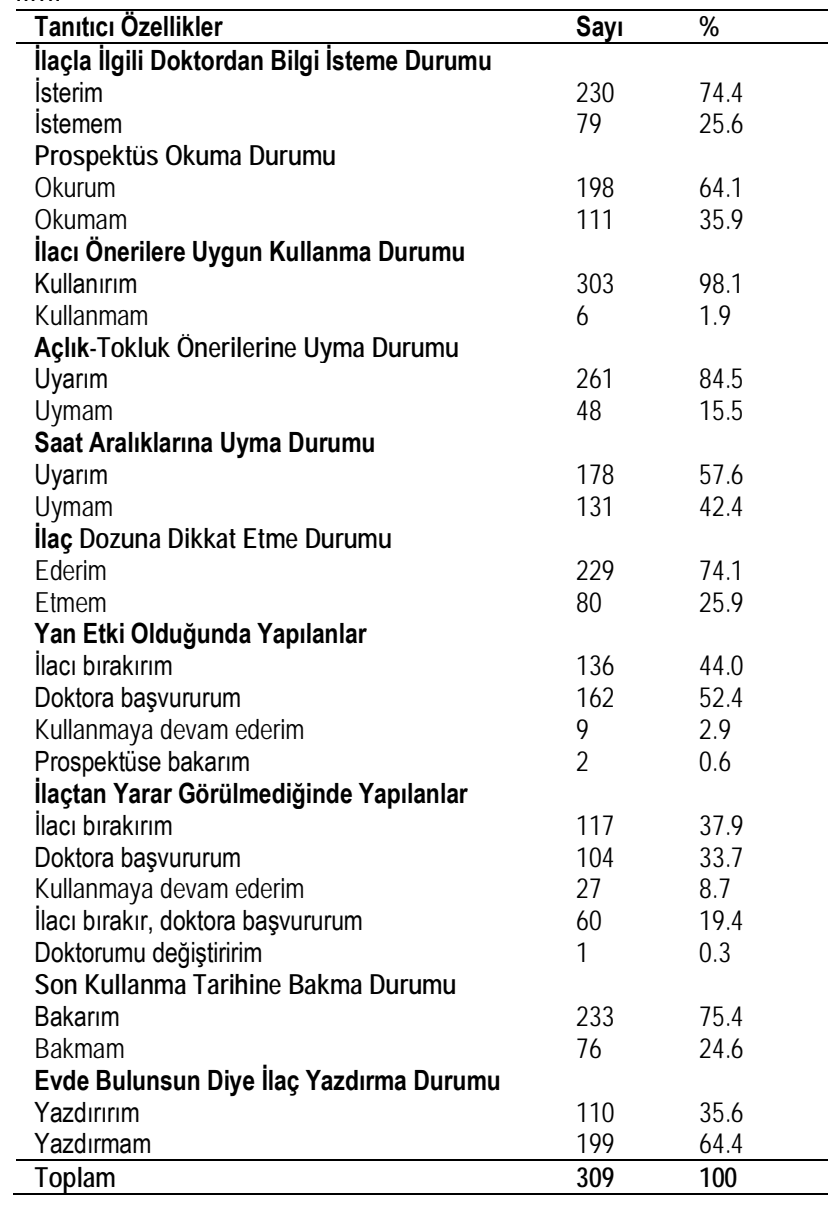

Gebelerin ilaç kullanım alışkanlıklarını etkileyebileceği düşünülen pek çok faktör incelenmiştir. Gebelerden üniversite mezunu olanların (\%36.4), evde en çok Kürtçe konuşanların (\%29.3), sosyal güvencesi olmayanların (\%26.9), ekonomik durumunu kötü olarak algılayanların (\%31.0), eşi üniversite ve üzeri eğitim düzeyine sahip olanların (\%35.0), eşi çalışanların (\%23.9), çekirdek ailede yaşayanların (\%25.5), köyde yaşayanların (\%24.5) ve tanı konulmuş kronik bir rahatsızlığı olanların (\%31.5) daha fazla doktora danışmadan ilaç kullandığı belirlenmiştir. Ancak, doktora danışmadan ilaç kullanma durumu ile; öğrenim durumu $(p=0.48)$, evde en çok konuşulan dil $(p=0.22)$, sosyal güvence $(p=0.46)$, algılanan ekonomik durum $(p=0.26)$, eşin öğrenim durumu ( $p=0.49)$, eşin çalışma durumu $(p=0.91)$, aile tipi $(p=0.51)$, yaşadığı yer $(p=0.96)$ ve tanı konulmuş kronik hastalığa sahip olma durumu $(p=0.19)$ açısından 
gruplar arasındaki fark istatistiksel olarak anlamsız bulunmuştur.

\section{Tartışma}

Gebelerin ilaç kullanımını etkileyen birçok faktör bulunmaktadır. Kullanılan ilaçlar hem annenin hem de fetüsün sağıIğını yakından ilgilendirdiğinden ve birçok ilacın potansiyel teratojenik etkisi henüz ortaya konulamadığından dolayı ele alınması gereken önemli bir konudur $(5,14)$.

Çalışmaya katılan gebeler çoğunlukla genç, eğitim ve ekonomik düzeyi düşük, çalışmayan ve sosyal güvenceye sahip olmayan kadınlardır. Sosyo-ekonomik özellikler ilaçların alınmasında ve doğru kullanımasında önemli belirleyicilerdir (15). Mollahaliloğlu ve Tezcan'ın yaptığı bir çalışmada sosyal güvencesi olanların doktora danışmadan antibiyotik kullanım oranını sosyal güvencesi olmayanlardan daha yüksek bulunmuştur (16). Ancak çalışmada sosyodemografik faktörlerin doktora danışmadan ilaç kullanımında etkisi olmadığı belirlenmiş̧tir. Bu sonuç, çalışmaya katılan gebelerin sosyo-demografik özelliklerinin birbirine çok benzer olmasından kaynaklanmış olabilir.

Çalışmada gebelerin \%76.1'inin gebeliği boyunca en az bir ilaç kullandığı görülmüştür. Hasta başına düşen ilaç maruziyetinin yüksek olması önemli bir bulgudur. Dünya genelinde ve Türkiye'de gebelikte ilaç kullanımı ile ilgili yapılan çalışmalara bakıldığında, çalışma ile paralellik göstermektedir. Başgül ve ark.'ının (17) Türkiye'de yaptığı çalışmada gebelerin \%80.5'inin ilaç kullandığı, Mitchell ve ark.'nın (18) Amerika'da yaptığı çalışmada 1978'den 2008'e kadar ilaç kullanan gebe oranının \%68.0 artıı̆ı, Lupatelli ve ark.'nın (19) Avrupa, Avustralya ve Amerika'da web-tabanlı uygulanan bir anket araştırmasında, gebelerin \%80.0'ının gebelik boyunca en az bir ilaç kullandığı belirtilmektedir. Gebelikte ilaç kullanım oranlarının bu kadar yüksek olmasında, takviye edici vitaminlerin etkisinin olabileceği düşünülmektedir. Nitekim çalışmada, gebeler tarafından kullanılan ilaçların başında vitaminler (\%60.5) gelmektedir.

Çalışmada doktora danışmadan ilaç kullanım durumu \%23.6 bulunmuştur. Abduelkarem ve Mustafa'nın Birleşik Arap Emirlikleri'nde yaptığı çalışmada (2017) gebelerin \%8.4'nün vitamin/mineral haricinde reçetesiz ilaç kullandığı belirtilmektedir (20). Çalışmamızla benzer şekilde Bercav ve ark.'nın İspanyol kadınlarının katılımı ile yaptıkları bir çalışmada (2010) gebelerin \%23.0'nün reçetesiz ilaç kullandığı (21), Abasiubong ve ark'nın Nijerya'daki çalışmasında (2012) ise gebelerin \%72.4'nün kendi kendilerine ilaç kullandıkları belirtilmektedir (22). Devkota ve ark'nın Nepal'de yaptığı bir çalışmada (2017) hastaların $\% 64.2$ 'sinde kendi kendilerine ilaç kullanma alışkanlıkları olduğu ancak bu hastaların \%75.5'inin gebelik süresince bu alışkanlığını değiştirdiği belirtilmektedir (23). Literatüre yansıyan bu sonuçlara bakıldığı zaman çalışmamızdaki gebelerin reçetesiz veya kendi kendine ilaç kullanma alışkanlıklarının (\%23.6) diğer ülkelere kıyasla daha az olduğu görülmektedir.

Çalışmada gebelerin \%24.9'u doktora sormadan antibiyotik kullanmaktadır. Antibiyotik kullanımı Çin'de \%6.5, Brezilya'da \%11.1, Etiyopya'da \%15.0, İtalya'da \%22.6 olarak bildirilmiştir (24-27). Bizim çalışmamızın oranları literatürle uyumlu bulunmuştur. Genel anlamda antibiyotik kullanımının bebeğe zarar verebileceği düşüncesi toplumda yaygındır. Doktora başvuru konusunda gebeleri bu ilaç grubu daha duyarlı hale getirmektedir. Çalışmada gebelerin doktorun önerdiği sürede antibiyotiği bırakma oranı da \%83.8 gibi yüksek orandadır. Pınar ve ark.'nın (2013) ile Şendir ve ark.'nın (2015) yaptığı çalışmada; hastaların iyileştiğini düşündüklerinde, kendini daha iyi hissettiklerinde ve daha fazla ilaç kullanmayı istemedikleri durumlarda doktorun önerdiği süreden önce ilaç kullanımını bıraktıkları görülmüştür ve bu durum araştırma sonuçları ile benzerlik göstermektedir $(28,29)$. Literatüre yansıyan bu sonuçlara bakarak ilaç kullanım alışkanlıkları değerlendiğinde olumsuz ve düzeltilmesi gereken bir durumdur. Diğer taraftan çalışmada gebeler ilaç önerilerine uyarken, açlık-tokluk önerilerine $\% 84.5$, saat aralıklarına $\% 57.6$, ilaç dozuna $\% 74.1$ dikkat ettiklerini belirtmişlerdir. Bu durumla ilgili gebelerin uyumlu tutumları bu konuya özenli ve akılcı davrandıklarını göstermektedir. Nepal' de Devkota ve ark.'nın yaptığı çaIışmada (2017) ise önerilere uyma konusunda \%54.6 oranda gebelerin daha düşük yüzde sergiledikleri görülmektedir (23).

Çalışmada gebelerin \%64.1'i prospektüs okuduğunu, $\% 51$.1'i ilaç endikasyonlarını okuduğunu belirtmiştir. Suudi Arabistan'da Zaki ve Albarraq (30) tarafindan yapılan bir çalışmada (2014) gebelerin \%86'sı; Türkiye'de Başgül ve ark.'nın (17) yaptığı çalışmada (2007) ise \%93,3'ü kullandıkları ilaçların prospektüsünü okuduklarını belirtmiştir. Literatüre yansıyan bu sonuçların aksine çalışmadaki gebelerin ilaç prospektüsünü okuma ve yan etkilere dikkat etme alışkanlıklarının daha düşük olması, ilaç kullanım alışkanIıklarının iyileştirimesi gereken bir durumdur.

Gebelikte ilaç kullanımı bilgi ve tutumlarının eğitim ile iyileştirilebileceğini gösteren çalışmalar vardır. Devkota ve ark.'nın Nepal'de yaptığı bir çalışmada (2017) gebelerin bilgi, tutum ve davranışları bu konuda eğitim aldıktan sonra istatistiksel olarak olumu artış gösterdiği gözlenmiştir (23).

\section{Sonuç ve öneriler}

Çalışmada, gebelerin çoğunluğunun doğru ilaç kullanım alışkanlığına sahip olduğu belirlenmiştir. Bu sonuçlar doğrultusunda, gebelerde doğru ilaç kullanımının yaygınlaştırılması, gebelik izlemlerinde ilaç kullanım alışkanlıklarının da sorgulanması, gerekli durumlarda ilaç kullanımına yönelik gebe ve ailesine eğitim ve danışmanlık yapılması, hemşirelerin ilaç kullanımı konusunda bilgilerinin güncel tutulması ve konuya duyarlııklarının artıılması önerilmiştir. Ayrıca; bilimsel ilaç araştırmalarının arttırıması, güncel bilgilerin takip edilmesi, dünya genelinde ve ülkede gebelikte 
döneminde ilaç kullanımı hakkında bir kayıt sisteminin belirlenmesi, güvenilir ve hızlı bir bilgi akışının olması, bilginin sağ ık personellerine ve gebelere doğru bir şekilde aktarım yapılması gerekenler arasındadır.

Etik Onam: Kamu Hastaneler Birliği Genel Sekreterliği'nden ve Harran Üniversitesi Etik Kurulu'ndan (01.09.2016 tarih ve 07 sayılı) yazılı izin, çalışmaya katımayı kabul eden gebelerden ise bilgilendirilmiş sözlü onam alınmıştır.

\section{Kaynaklar}

1.Mitchell AA, Gilboa SM, Werler MM et al. National birth defects prevention study. Medication use during pregnancy, with particular focus on prescriptiondrugs: 1976-2008. Am J Obstet Gynecol 2011;205(1):5158.

2.Pacheco LD, Costantine MM, Hankins GD. Physiologic changes during pregnancy. In: Mattison D, editör. Clinical pharmocology during pregnancy. USA: Elsevier; 2013. p. 5-16.

3.Ede G, Ünal RN. Gebelik döneminde fizyolojik ve farmakokinetik değişiklikler ile ilaç-besin ögesi etkileşimler. İstanbul Med J 2017; 18:2017.

4.Stevenson Roger E. The genetic basis of human anomalies. In: Stevenson RE, Hall JG, Goodman RM, eds. Human malformations and related anomalies 1st ed. Oxford: Oxford University Press; 1993. p.21.

5.Irvine L, Flynn RW V, Libby G, Crombie IK, Evans JMM. Drugs dispensed in primary care during pregnancy. Drug Saf. 2010; 33:593-604. 6.Göv N. Şanlıurfa'da bir aile sağlığı merkezinde riskli gebelik sıklığı ve etkileyen faktörler, Yüksek lisans Tezi, Harran Üniversitesi, 2016, Şanliurfa.

7. Olukman M, Parlar A, Orhan CE, Orhan AE. Gebelerde ilaç kullanımı: son bir yıllık deneyim. J Turk Soc Obs. Gynecol 2006; 3:255-261.

8.Akdeniz N, Kale A, Erdemoglu M, Yalcinkaya A, Yayla M. Retrospective analysis of the 126 cases terminated in pregnancy by the ethical committee decision. Perinatal Journal 2005; 13(2):80-5.

9.De Santis M, Cesari E, Ligato MS, Nobili E, Straface G, Cavaliere A, et all. Prenatal drug exposure and teratological risk: one-year experience of an Italian Teratology Information Service. Med. Sci. Monit. 2008;14: $\mathrm{H} 1-\mathrm{H} 8$

10.Toklu ZH, Akıcı A, Uysal MK, Dülger Ayanoğlu G. Akılcı ilaç kullanımı sürecinde hasta uyumuna hekim ve eczacının katkısı. Türk Aile Hekimliği Dergisi 2010;14(3):139-145.

11. Hancock RL, Koren G, Einarson A, Ungar WJ. The Effectiveness of Teratology Information Services (TIS). Reprod. Toxicol 2007; 23:125132

12.Ujházy E, Mach M, Navarová J, Brucknerová I, Dubovický M. Teratology - past, present and future. Interdiscip. Toxicol 2012; 5:163-168. 13. Hacettepe Üniversitesi Nüfus Etütleri Enstitüsü. Türkiye Nüfus ve Sağlık Araştırması 2013. Erişim yeri: http://www.hips.hacettepe.edu.tr/tnsa2013/rapor/TNSA_2013_ana_rapor.pdf.

14.Oray N. [Drug use in pregnancy]. TATD Klinik Toksikoloji Sempozyumu. DEÜTF Acil Tıp Ad. Nisan 2014.

15.Yılmaz M, Güler N, Güler G, Kocataş S. Bir grup kadının ilaç kullanımı ile ilgili bazı davranışları akılcı mı? Cumhuriyet Tıp Dergisi 2011; 33: 266-77.

16.Mollahaliloğlu S, Tezcan S. Ankara il merkezinde bulunan sağık ocaklarında çalışan hekimlerin akılcı ilaç kullanımı açısından değerlendirilmesi, 8.Ulusal Halk Sağığı Kongresi Bildiri Kitabı. 23-28 Eylül 2002, Diyarbakır, s. 499-501.

17.Basgul A, Akici A, Uzuner A, Kalaça S, Kavak ZN, Tural A, Oktay S. Drug utilization and teratogenicity risk categories during pregnancy. Advances in Therapy.2007; 24(1):68-80.

18. Mitchell AA, Gilboa SM, WerlerMM. Medication use during pregnancy, with particular focus on prescription drugs: 1976-2008. Am J
Obstet Gynecol.2011;205(1):1-8.

19.Lupattelli A, Spigset O, Twigg MJ, Zagorodnikova K, Mardby AC, Moretti ME, et all. Medication Use in Pregnancy: across-sectional, multinational web-based study. Br Med J. 2014;4(2): e004365.

20.Abduelkarem AR, Mustafa $\mathrm{H}$. Use of over the counter medication among pregnant women in Sharjah, United Arab Emirates. J of Pregnancy. 2017;1: 1-8.

21.Bercaw J, Maheshwari B, Sangi-Haghpeykar H. The use during pregnancy of prescription, over the counter and alternative medications among Hispanic women. Birth. 2010;37: 211-218.

22.Abasiubong F, Bassey EA, Udobang JA, Akinbami OS, Udoh SB, Idung AU. Selfmedication: potential risks and hazards among pregnant women in Uyo, Nigeria. Pan Afr Med J. 2012;13: 15.

23.Devkota R, Khan GM, Alam K, Sapkota B, Devkota D. Impacts of counseling on knowledge, attitude and practice of medication use during pregnancy. BMC Pregnancy and Childbirth. 2017;17: 131.

24.Göker A, Kadıoğlu DM, Gürpınar T, Muci E, Yıldırım Y, Erköseoğlu İ, ve ark. Gebelikte ilaç kullanımı nedeni ile başvuran hastaların değerlendirilmesi. Journal of: Clinical Obstetrics\&Gynecology. 2012;22(2):9094.

25.Mengue SS, Schenkel EP, Duncan BB, Schmidt MI. [Drug use by pregnant women in six Brazilian cities]. Rev Saude Publica 2001;35(5):415-20.

26.Zhu X, Qi X, Hao J, Huang Z, Zhang Z, Xing X, et al. Pattern of drug use during the first trimester among Chinese women: data from a population-based cohort study. Eur J Clin Pharmacol 2010;66(5):511-8.

27.Gagne JJ, Maio V, Berghella V, Louis DZ, Gonnella JS. Prescription drug use during pregnancy: a population-based study in Regione Emilia-Romagna, Italy. Eur J Clin Pharmacol 2008;64(11):1125-32.

28.Pınar N, Karataş Y, Bozdemir N, Ünal İ. Adana ilindeki insanların ilaç kullanım alışkanlıkları. TAF Preventive Medicine Bulletin. 2013;12(6):639-50.

29.Şendir M, Çelik Z, Güzel E, Büyükyılmaz F. Aile sağlığı merkezlerine başvuran bireylerde akılcı ilaç kullanım alışkanlıklarının belirlenmesi. TAF Preventive Medicine Bulletin. 2015;14(1):15-22.

30.Zaki NM, Albarraq AA. Use, attitudes and knowledge of medications amoung pregnant women: A Saudi Study. Saudi Pharmaceutical Journal. 2014;22: 419-428. 